\title{
ANÁLISE ECONÔMICA DA EVOLUÇÃO HISTÓRICA DA ERVA-MATE EM MATO GROSSO DO SUL
}

\author{
Rayan Wolf* \\ Matheus Wemerson Gomes Pereira**
}

RESUMO: O presente trabalho buscou analisar os motivos que levaram a erva-mate passar de um produto chave na economia do estado de Mato Grosso do Sul para um produto sem relevância do ponto de vista econômico para o estado, analisando o atual cenário da erva-mate. Objetivou-se especificamente analisar o atual cenário econômico da erva-mate no estado, mensurar as correlações entre a produção da erva-mate no Mato Grosso do Sul e outros estados e países, fazer a previsão para produções futuras, e como objetivo geral, identificar os motivos que levaram a ervamate perder espaço na atual economia de Mato Grosso do Sul. As hipóteses são que a perda de importância econômica da erva-mate no estado ocorreu devido à concorrência com outras regiões produtoras, e com outras culturas a erva-mate possui um processo produtivo competitivo. Os resultados indicam que a erva-mate produzida no estado de Mato Grosso do Sul está perdendo espaço para outros estados e países e também para outras culturas, sendo que a produção de erva-mate possui uma tendência negativa.

PALAVRAS-CHAVE: Erva-mate; Mato Grosso do Sul; Produção.

\section{ECONOMIC ANALYSIS OF THE HISTORICAL EVOLUTION OF THE YERBA MATE PLANT IN MATO GROSSO DO SUL}

ABSTRACT: Current investigation deals with the motives underlying the fact that the yerba-mate plant in the state of Mato Grosso do Sul, Brazil, passed from a key economical product to a non-relevant one within the economical perspective of the state. Current economic situation of yerba mate is investigated and the corelationships between yerba-mate production in Mato Grosso do Sul and in other Brazilian states and in other countries are assessed, with future perspectives. Further, the reasons why yerba mate is currently less important for the state's

\footnotetext{
"Mestrando em Administração na Universidade Federal de Mato Grosso do Sul (UFMS), Brasil; E-mail: wolf.ry@ gmail.com

${ }^{* *}$ Doutor em Economia Aplicada pela Universidade Federal de Viçosa (UFV), Brasil; Docente Adjunto da Universidade Federal de Mato Grosso do Sul (UFMS), Brasil.
} 
economy are investigated. Loss of importance was due to competition with other producing regions and with other cash crops within a competitive market economy. Results show that the yerba mate produced in the state of Mato Grosso do Sul is less competitive and its production tends to be negative.

KEY WORDS: Yerba mate; Mato Grosso do Sul; Production.

\section{INTRODUÇÃO}

Após a Guerra do Paraguai, foi criada uma comissão mista de paraguaios e brasileiros, no intuito de redesenhar os limites entre os dois países. Esta tarefa foi finalizada no ano de 1872, e Thomaz Laranjeira esteve presente nesse processo, sendo possível que o mesmo avaliasse bem a área fronteiriça e, em meio a terras indígenas, encontrou extensos ervais nativos de erva-mate (SEREJO, 1984).

Enquanto a pecuária serviu para abastecer a região Sudeste, os primeiros passos do grande capital na região Sul do estado de Mato Grosso ocorreram tendo a erva-mate como um dos principais produtos. Desta forma, a criação da Companhia Mate Laranjeiras influenciou o surgimento de povoados e pequenas vias de rodovias e ferrovias, sendo de extrema importância para o processo de desenvolvimento local (ZAMBERLAN et al., 2010).

No ano de 1883 inicia-se o Ciclo Econômico da erva-mate em Mato Grosso do Sul (SEREJO, 1984). A produção de erva-mate cancheada saía da região e seguia para a Argentina, o principal mercado consumidor. Devido à presença e atividades da grande empresa realçada, possuía o domínio quase exclusivo sobre a produção e a exportação da erva-mate (FERNANDES, 2003). A produção de erva-mate em Mato Grosso do Sul, entre 1880 e 1937, chegou, em média, a 227.798 toneladas, gerando, entre 1882 e 1937, um alto valor de exportação (ARRUDA, 1984).

Considera-se que o Ciclo Econômico da erva-mate perdurou até 1947, no entanto, sabe-se que a produção ervateira persistiu por anos, até depois de 1965, e ainda nos dias de hoje em condições diferentes (ARRUDA, 1984), ainda que, a partir de 1966, o estado de Mato Grosso do Sul deixasse de exportar o produto para o seu principal mercado consumidor, a Argentina. Existe hoje uma infinidade de usos industriais identificados para a erva-mate (BALDO, 2012), com produtos que vão 
desde variadas bebidas até medicamentos e cosméticos.

A grande questão a ser explorada é que a erva-mate apresentava uma produção, que foi capaz de trazer desenvolvimento econômico local para o estado do Mato Grosso do Sul (especificamente a região Sul do antigo estado de Mato Grosso), porém, nas últimas décadas, ocorreu uma redução de sua produção. $\mathrm{O}$ presente trabalho, então, buscará analisar os motivos que levaram a erva-mate passar de um produto chave na economia de Mato Grosso do Sul para um produto sem relevância do ponto de vista econômico no estado, procurando analisar o atual cenário econômico da erva-mate no estado.

Com base nas hipóteses de que a erva-mate perdeu espaço na economia sul-mato-grossense em virtude da substituição por outras culturas, e devido à forte concorrência de outros estados brasileiros e outros países, objetivou-se especificamente analisar o atual cenário econômico da erva-mate no estado, mensurar as correlações entre a produção da erva-mate no Mato Grosso do Sul e em outros estados e países, fazer a previsão para produções futuras e, como objetivo geral, identificar os motivos que levaram a erva-mate perder espaço na atual economia de Mato Grosso do Sul.

Para alcançar os objetivos do presente trabalho, adotaremos o modelo produto-produto, que considera a possibilidade de produção conjunta de vários produtos (DOS SANTOS; LÍRIO; VIEIRA, 2009). Em Mato Grosso do Sul, constata-se a existência da produção conjunta de diversas culturas, como o caso da erva-mate, soja, milho e cana-de-açúcar, que concorrem pelos mesmos insumos, considerando que todos são produtos provenientes da agricultura.

\subsection{MODELO PRODUTO-PRODUTO}

As justificativas para a produção de vários produtos podem ser: i) Economia de escopo; ii) Utilização conjunta das instalações e do emprego de insumo comuns; iii) Participação em diversos mercados, ou nichos de mercado; iv) Redução do risco, devido à diversificação de investimento na produção multiprodutos; v) Exploração eficiente das oportunidades de realização de negócios, ou de realização de lucros (DOS SANTOS; LÍRIO; VIEIRA, 2009).

Com a possibilidade de usar insumos produtivos em proporções 
diferentes na produção de mais de um produto, além disso, insumos que seriam utilizados somente no processo produtivo de um único produto, agora possuem a possibilidade de serem empregados na produção de outra mercadoria; surge aí o conceito de curva de possibilidade de produção (DOS SANTOS; LÍRIO; VIEIRA, 2009).

A CPP (curva de possibilidades de produção) é definida com o espaço geométrico, que une as combinações de produção de $y_{1}$ e $y_{2}$ com possibilidade de obtenção do mesmo montante de recursos. Qualquer combinação entre as produções, sobre a CPP reflete um mesmo custo de produção, apenas com diferentes quantidades produzidas de cada produto.
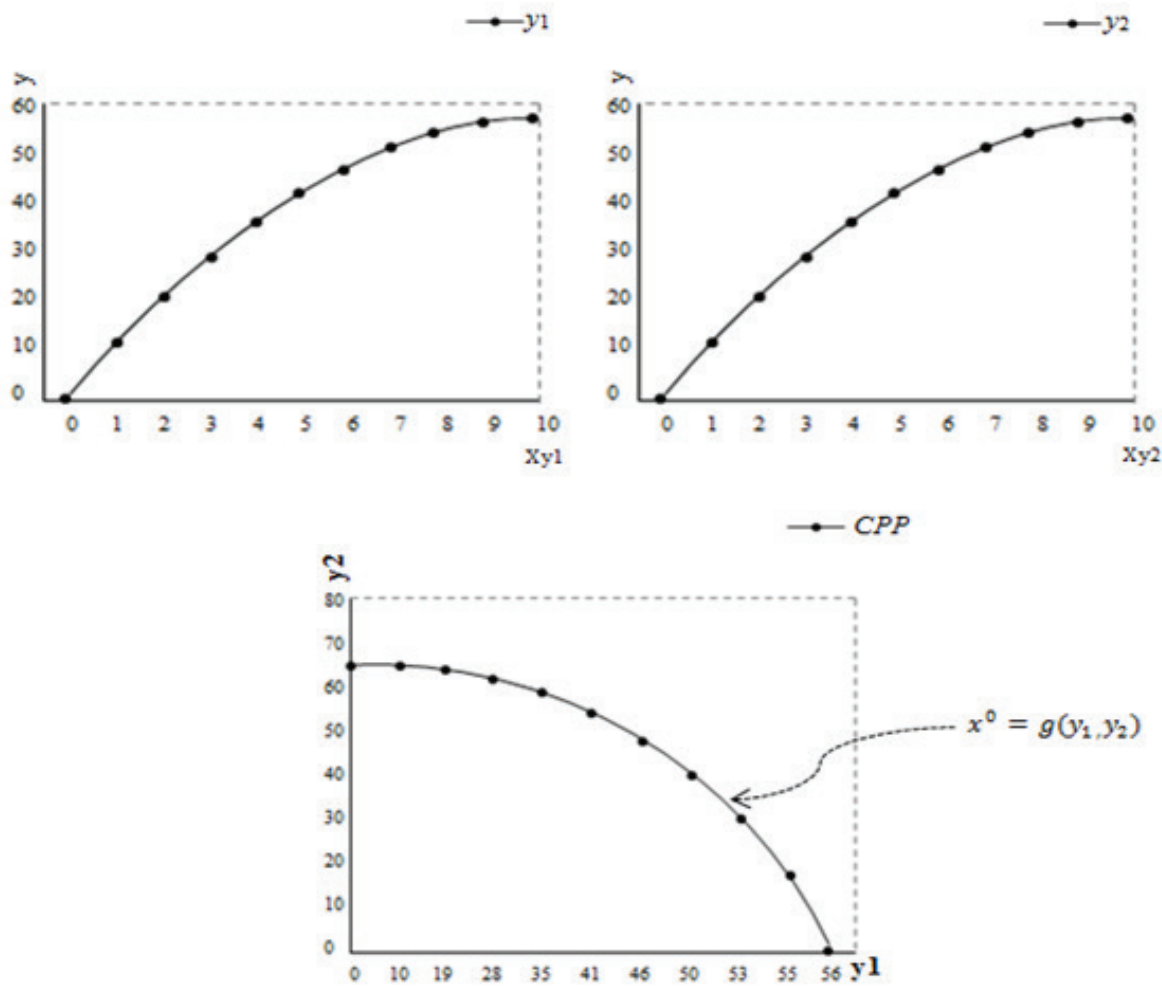

Figura 1. Representação das funções produção de A, B e Curvas de Possibilidades de Produção Fonte: Dos Santos, Lírio e Vieira (2009). Adaptado pelos autores. 
Para qualquer quantidade de insumos, a CPP pode ser representada por uma função implícita do tipo: $x^{0}=g\left(y_{1}, y_{2}\right) x^{0}=g\left(y_{1}, y_{2}\right)$, sendo que à medida que os insumos destinados à produção de $\mathrm{A}$ são destinados para a produção de B, ocorre uma transformação de A em B. Considerando a transformação de um produto em outro, obtém-se a Taxa Marginal de Transformação, sendo medida em valor absoluto, através da variação na produção de A $\left.\left(\Delta y_{1}\right) \Delta y_{1}\right)$, dividida pela produção de $\left.\mathrm{B}\left(\Delta y_{2}\right) \Delta y_{2}\right)$.

A Taxa Marginal de Transformação (TMT) é positiva e, à medida que A se transforma em B, se torna cada vez maior. Assim, a TMT pode ser definida como o negativo da CPP, uma vez que a inclinação da CPP é negativa. A TMT depende do formato da CPP, e, assim, das possibilidades de combinação ou não dos insumos na produção multiproduto. Se a CPP for negativa, a TMT é positiva, caso contrário, se a CPP for positiva, a TMT se torna negativa. A Taxa Marginal de Transformação pode ser definida também como o montante que se deixa de produzir de um determinado produto para produzir uma unidade adicional de outro.

Os processos produtivos competitivos são caracterizados pela impossibilidade de aumentar a produção em B sem sacrificar a produção em A, ou seja, a produção de A é concorrente da produção de $\mathrm{B}$, uma prejudica a outra. $\mathrm{O}$ que ocorre, neste caso, é o sacrifício da produção de um dos bens de acordo com as expectativas de preço de mercado.

Os processos produtivos complementares são caracterizados pela possibilidade de produção de dois produtos de forma simultânea, sem que o aumento na produção de A prejudique a produção em B. Nesse tipo de processo, seria sempre vantajoso aumentar a produção até que se esgotassem as possibilidades de se alterar a produção sem alterações no custo (DOS SANTOS; LÍRIO; VIEIRA, 2009).

\section{MATERIAL E MÉTODO}

O presente artigo parte de uma questão particular e chega a conclusões generalizadas sem criar novas leis ou teorias, tendo como método a ser utilizado o indutivo conforme definido por Lakatos e Marconi (2006). Utilizar-se-á ferramentas 
de estatística descritiva, que têm como principal objetivo a redução de dados, visando traduzir informações de relevância, que estejam em uma grande base de dados, por meio de números menores, valores, ou através de gráficos simples e tabulações que simplifiquem o problema (PETERNELLI, 2008).

As seguintes estatísticas descritivas serão apresentadas no trabalho: média, variância, desvio padrão, covariância e correlação. Para a previsão futura da produção de erva-mate no Mato Grosso do Sul, será utilizada série de tempo, que consiste na observação de uma ou mais variáveis ao longo do tempo. Torna-se importante atentar para a frequência dos dados a serem observados na série temporal (PEREIRA, 2011). No caso do presente artigo, os dados de quantidade produzida, tanto de ervamate quanto de demais produtos são anuais, compreendendo um período de tempo de vinte e dois anos (1990-2011), coletados no Instituto Brasileiro de Geografia e Estatística (IBGE).

O modelo de previsão será estimado pelo método de mínimos quadrados ordinários (MQO) ${ }^{1}$ e o tipo de tendência adotada será a estocástica, que representa uma tendência que apresenta variação aleatória ao longo do tempo. Modelos que incorporam tendência estocástica são modelos denominados de passeio aleatório (LIMA, 2009).

O enfoque clássico ou tradicional para análise de séries temporais consiste em decompor a série em quatro componentes não observáveis: i) Tendência (T); ii) Variações Sazonais (S); iii) Variações Cíclicas (C); iv) Variações Irregulares (I) (LIMA, 2009).

A maneira como se efetivam as relações entre esses componentes pode variar de uma série para outra, podendo ser encontradas relações aditivas ou multiplicativas entre os componentes. Utilizaremos o Modelo Aditivo, onde o valor da série será o resultado da soma dos valores das componentes. No modelo aditivo é adequado quando as variações sazonais não dependem de outras variáveis (MILESKI JUNIOR, 2007).

\subsection{CARACTERIZAÇÃO DA ÁREA DE ESTUDO}

Estabelecido ao sul da região Centro-Oeste, o estado de Mato Grosso do Sul encontra-se em uma localização estratégica, tendo como limite os maiores centros 
consumidores do país: São Paulo, Paraná e Minas Gerais; além de ter grande parte do território situado em fronteiras com os principais países do MERCOSUL, outro fator importante para angariação de investimentos.

O estado está integrado por três eixos rodoviários federais, duas ferrovias e duas hidrovias. Possui 70\% do Pantanal, formado por três biomas: Cerrado, Chaco Boliviano-Paraguaio e Floresta Amazônica. Possui uma hidrografia excepcional formada pelo Aquífero Guarani e palas bacias do Rio Paraguai e do Rio Paraná.

Mesmo com uma conjuntura econômica frágil devido à crise ocorrida em 2008, em 2009 o PIB de Mato Grosso do Sul foi de R $\$ 36.368$ bilhões, o que representou um crescimento tímido de $0,42 \%$, muito abaixo da média que se estendeu de 2003 a 2008, crescimento de 4,68\% ao ano. Na composição do Produto Interno Bruto o Setor Terciário teve participação em 65,99\%, o Setor Secundário 18,48\%, e o Setor Primário, agropecuária, 15,53\%, sendo que a agricultura foi bastante prejudicada, apresentando uma retração de 36,32\% se comparada ao ano anterior (SEMAC). A capital, Campo Grande, tem quase que um terço das riquezas do estado, com $\mathrm{R} \$$ 11,6 bilhões em 2009. Em seguida aparecem as cidades de Dourados, com R\$ 3 bilhões; Corumbá, 2,7 milhões; e Três Lagoas, com R\$2 bilhões (IBGE).

A partir do final do século XIX, o crescimento da produção da ervamate, que passou de extrativismo artesanal para uma escala industrial, através da Companhia Matte-Laranjeira, resultou no crescimento das cidades do Sul do estado, como Porto Murtinho, Ponta Porã, Dourados, Bela Vista. Por volta de 1895, muitas famílias provenientes do estado do Rio Grande do Sul, chegavam à região Sul de Mato Grosso, criando polos agrícolas na região da Grande Dourados e de pecuária na região da cidade de Naviraí. Podemos observar a ocupação do estado por meio da Figura 2. 

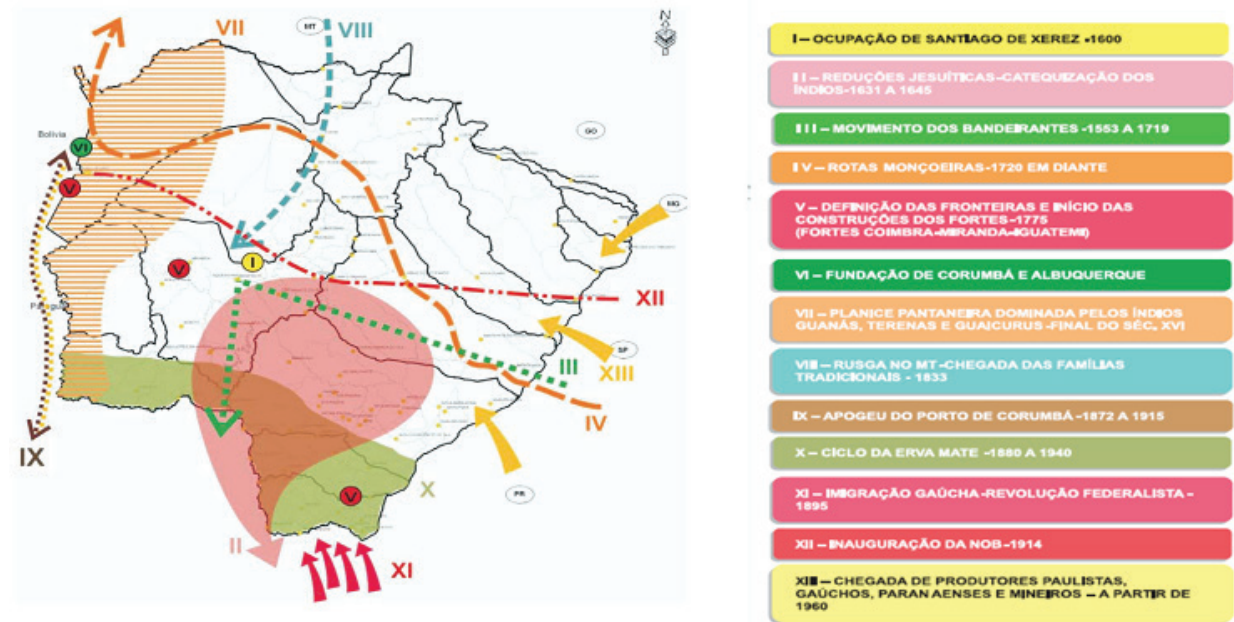

Figura 2. Mapa da ocupação do estado de Mato Grosso do Sul Fonte: Zoneamento Ecológico Econômico de Mato Grosso do Sul, Governo do Estado de Mato Grosso do Sul (Adaptado pelos autores).

Serão consideradas apenas as cidades produtoras de erva-mate: Amambai, Antônio João, Aral Moreira, Bela Vista, Caarapó, Caracol, Coronel Sapucaia, Dourados, Eldorado, Fátima do Sul, Iguatemi, Itaquiraí, Japorã, Juti, Laguna Carapã, Maracaju, Miranda, Mundo Novo, Naviraí, Paranhos, Ponta Porã, Sete Quedas e Tacuru. A produção de erva-mate, soja, milho e cana-de-açúcar, na região estudada, pode ser observada na Tabela 1 .

Tabela 1. Quantidade produzida de cada cultura entre 1990 e 2009

\begin{tabular}{ccccc}
\hline ANO & \multicolumn{4}{c}{ Quantidade total produzida por período (ton.) } \\
\hline & Erva-mate & $\underline{\text { Soja }}$ & $\underline{\text { Milho }}$ & Cana-de-açúcar \\
\hline $\mathbf{1 9 9 0 - 1 9 9 9}$ & 29.585 & 8.594 .469 & 5.217 .328 & 14.272 .779 \\
$\mathbf{2 0 0 0 - 2 0 0 9}$ & 11.877 & 18.464 .920 & 11.780 .597 & 38.255 .204 \\
\hline
\end{tabular}

Fonte: IBGE (2013)

Percebe-se que nos últimos nove anos o único produto que teve uma queda em sua produção foi a erva-mate, mesmo considerando somente as regiões 
produtoras de erva-mate, enquanto soja, milho e cana-de-açúcar apresentaram um aumento em suas produções.

Os dados secundários serão buscados em dados disponibilizados pelo estado de Mato Grosso do Sul, pelo Instituto Brasileiro de Geografia e Estatística (IBGE, 2013), Organização de Alimentação e Agricultura das Nações Unidas (FAOSTAT, 2011).

\section{RESULTADO E DISCUSSÃO}

\subsection{PRODUÇÃO DE ERVA-MATE E OUTRAS CULTURAS EM MATO GROSSO DO SUL}

Ao analisar a produção de erva-mate, soja, milho e cana-de-açúcar, observa-se que, em relação aos produtos cultivados nas áreas do estado onde se produz erva-mate, a soja, a cana-de-açúcar e o milho apresentaram entre 1990 e 2011 uma produção crescente, com destaque para a cana-de-açúcar, que a partir de 2002 aumentou sua produção em mais de dez vezes o que produzia em 2001, como se pode observar na Figura 3.

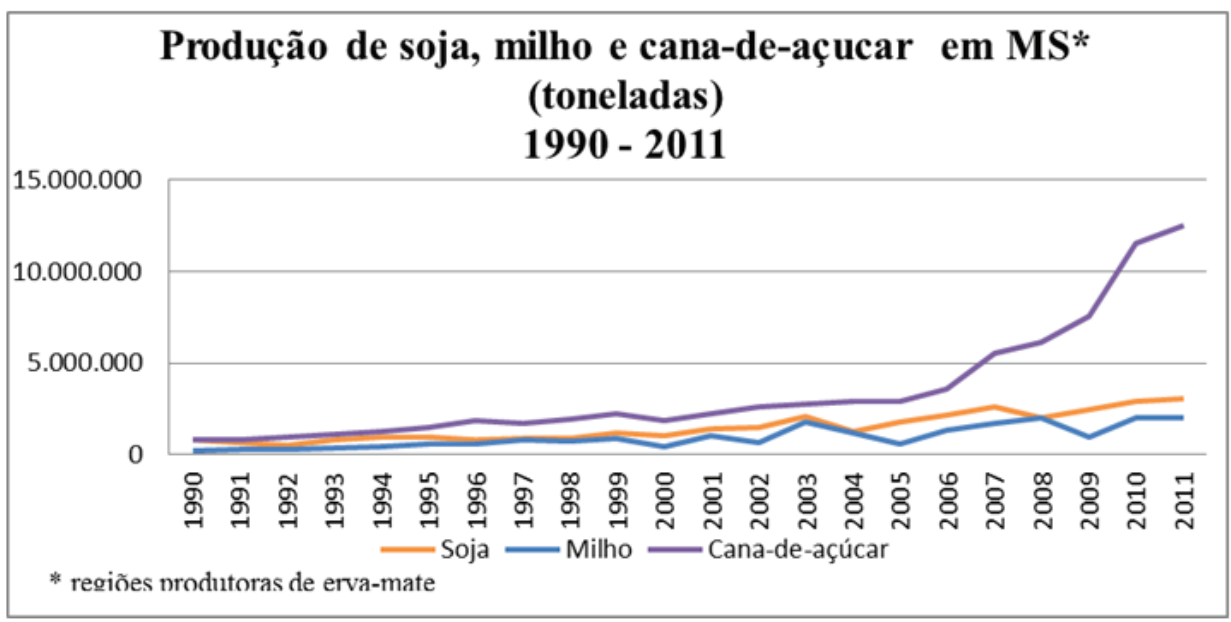

Figura 3. Produção de soja, milho e cana-de-açúcar em Mato Grosso do Sul Fonte: IBGE (2013). Elaborado pelos autores. 
Quando se analisa a produção da erva-mate, observa-se um cenário completamente diferente: entre 1990 e 2011, a produção, que durante esse período sempre esteva abaixo da produção das outras culturas, decaiu de 4.765 toneladas para 436 toneladas, ainda que em 2001 e 2002 esboçasse um pequeno aumento na quantidade que vinha sendo produzida, como se pode observar na Figura 4.

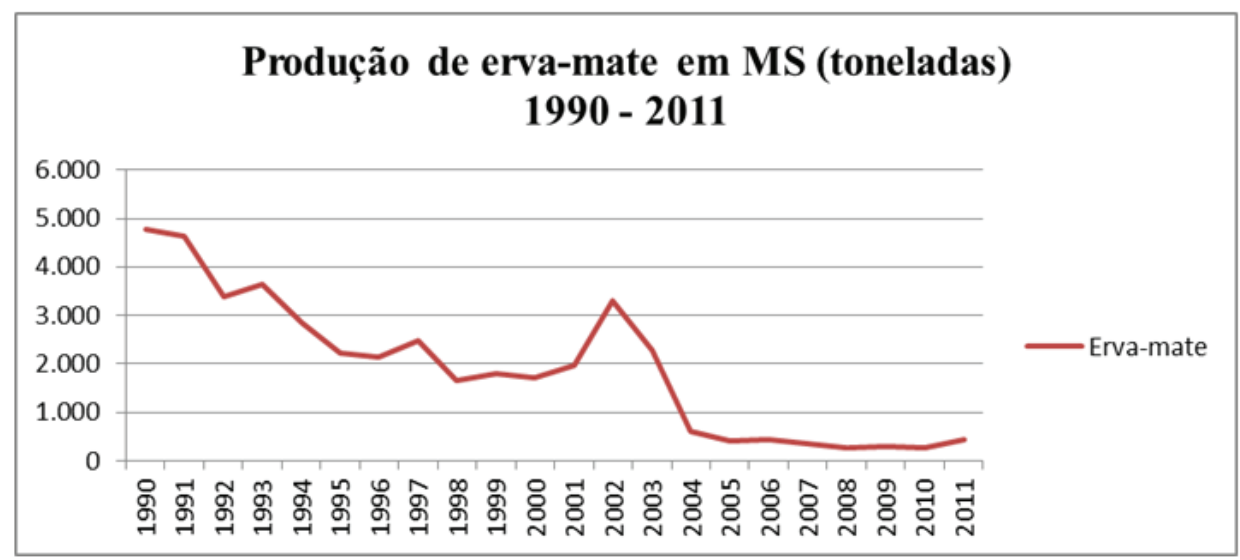

Figura 4. Produção de erva-mate em Mato Grosso do Sul Fonte: IBGE (2013). Elaborado pelos autores.

3.2 PRODUÇÃO DE ERVA-MATE EM MATO GROSSO DO SUL, PARANÁ, SANTA CATARINA E RIO GRANDE DO SUL

O gráfico com a produção de erva-mate em Mato Grosso do Sul, Santa Catarina, Rio Grande do Sul, Paraná, Argentina e Paraguai pode ser observado na Figura 5. 


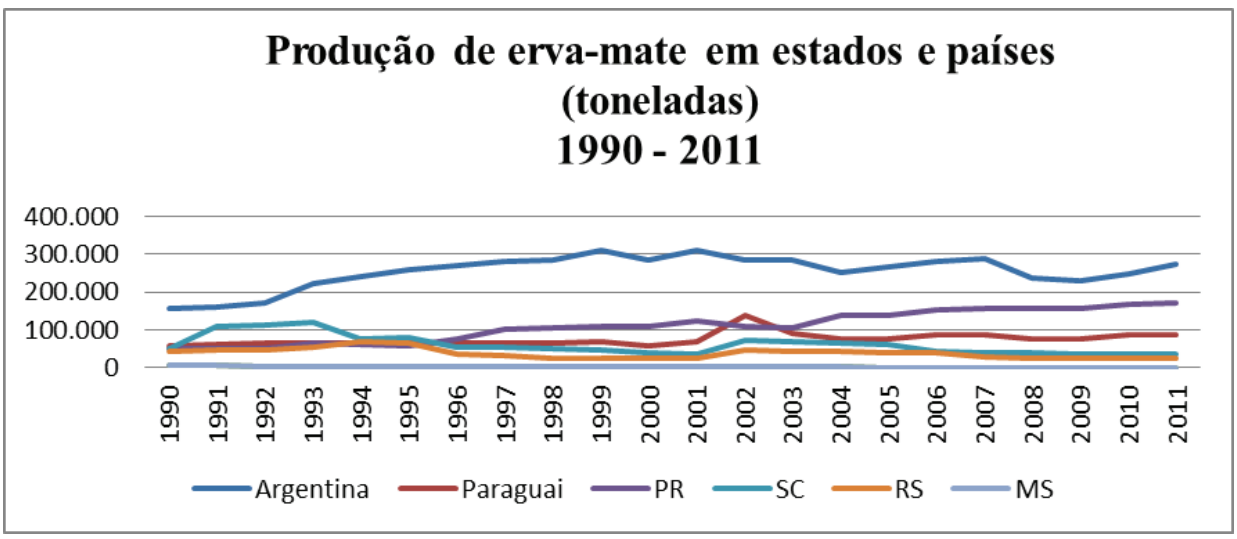

Figura 5. Produção de erva-mate em estados e países Fonte: IBGE (2013). Elaborado pelos autores.

Quando se observam os aspectos concorrenciais com outros estados, nota-se que o estado do Paraná, no ano de 1990, era o maior produtor de erva-mate. No entanto, de 1991 até o ano de 1995, se tornou o segundo maior produtor de erva-mate brasileiro, quando Santa Catarina foi o maior produtor nacional. A partir de 1996, o estado se consolidou na primeira posição entre os produtores brasileiros, com uma produção de 169.549 toneladas no ano de 2011, representando uma produção que, mesmo não sendo o maior estado com área plantada, é o maior em quantidade produzida, com $73,82 \%$ de toda a produção nacional.

O segundo maior produtor de erva-mate é o estado de Santa Catarina, com a produção atingindo em 2011 a quantidade de 36.117 toneladas, 15,72\% da produção total do Brasil. Entre 1991 e 1995, o estado se manteve no posto de maior produtor de erva-mate brasileiro. O estado de Santa Catarina possui todo o suporte dado pela Empresa de Pesquisa Agropecuária e Extensão Rural, que fornece pesquisa, extensão e informações, que contribuem muito para a manutenção da produtividade da erva-mate no estado.

O estado do Rio Grande do Sul está na terceira posição se levar em consideração a produção brasileira. O estado, que produziu 23.579 toneladas em 2011, representando 10,26\% da produção nacional. O estado devastou uma grande área de ervais para a implantação de culturas de grãos, e somente o uso de técnicas modernas de adensamento e recuperação dos ervais degradados poderá reverter esse quadro no estado, que tem um grande potencial para o cultivo da erva-mate. 
Mato Grosso do Sul encontra-se na quarta posição, produzindo 436 toneladas em 2011, o que representa $0,18 \%$ do total produzido no país. A produção teve uma queda drástica entre o início e o final do intervalo de tempo. As causas são diversas, e discutidas neste trabalho. A colheita no estado é feita de forma extrativista, sem levar em consideração o tempo de recuperação das árvores, nem conta com técnicas avançadas de podas. $\mathrm{O}$ estado apresenta um grande potencial para o desenvolvimento da cultura da erva-mate, no entanto, entre os quatro produtores, é o que menos investe em pesquisa, e não se preocupa diretamente com o desenvolvimento do setor.

Em relação aos outros países, pode-se concluir que a produção argentina de erva-mate em 2011 chegou a 272.619 toneladas. O mercado interno absorve $83,42 \%$ da produção, considerando que, em 2009, o país produziu 228.499 toneladas e exportou apenas 37.883 toneladas de erva-mate (FAOSTAT, 2012). A Argentina é a maior produtora de erva-mate do mundo.

A produção de erva-mate paraguaia aumentou de 57.182 toneladas em 1990 para 85.182 em 2011, um aumento de $48,97 \%$. O consumo interno do produto produzido no país é muito expressivo, levando em conta que as exportações em 2009 representaram apenas $0,77 \%$ do total produzido, e as importações representaram apenas 41 toneladas, ou seja, quase 100\% do consumo de erva-mate consumida no Paraguai advêm da própria produção do país (FAOSTAT, 2012).

Tanto a Argentina como o Paraguai, ao contrário do que se observa no estado de Mato Grosso do Sul, apresentaram um crescimento na produção ao final da série de tempo, mesmo que, ao longo do período estudado, não tenha sido frequente o crescimento na produção; no ano de 2011, a produção dos dois países apresentou valores maiores do que em 1991. No caso da Argentina, os anos que mais foi produzida erva-mate foram em 1999 e 2001, quando produziu 310.000 toneladas; já o Paraguai, no ano de 2002, produziu a quantia de 136.589 toneladas.

\subsection{ESTATÍSTICA DESCRITIVA}

\subsubsection{Análise entre Erva-mate e outras Culturas Produzidas em Mato Grosso do Sul}

A Tabela 2 resume os dados estatísticos de erva-mate e demais culturas produzidas em Mato Grosso do Sul. 
Tabela 2. Estatística descritiva para as culturas produzidas em Mato Grosso do Sul*

\begin{tabular}{lccccc}
\hline Variável & Obs. & Média & Desvio Padrão & Mínimo & Máximo \\
\hline Erva-mate & 22 & 1940,455 & 1431,186 & 275 & 4765 \\
Soja & 22 & 1502829 & 776030,3 & 550841 & 3077882 \\
Milho & 22 & 955776,5 & 602987,7 & 198216 & 2031969 \\
Cana-de-açúcar & 22 & 3385391 & 3332458 & 227769 & 12500000 \\
\hline
\end{tabular}

*plantada nas regióes produtoras de erva-mate

Fonte: Elaborado pelos autores.

Ao analisar a Tabela 2, nota-se que, nas regióes produtoras de erva-mate, a cana-de-açúcar apresentou a maior média na produção, produzindo, em média, 3.385.391 toneladas ao longo dos vinte e dois anos estudados, produzindo um mínimo de 227.769 toneladas e um máximo de 12.500 .000 toneladas. O desvio padrão indica que os dados referentes à produção de cana-de-açúcar não se encontram tão dispersos, ou seja, não apresentam grandes variações durante o período.

A segunda maior cultura produzida na região foi a soja, com uma média de 1.502.829 toneladas produzidas de 1990 a 2011, sendo que a quantidade mínima produzida foi de 550.841 toneladas e um máximo de 3.077 .882 toneladas. O desvio padrão indica que a quantidade produzida varia bastante ao longo do tempo.

O milho apresenta a terceira maior produção da região, com a quantidade média produzida atingindo $955.776,5$ toneladas entre os anos observados, com um valor mínimo de 198.216 toneladas e o máximo de 2.031.969 toneladas; o desvio padrão indica que os valores de quantidade produzida variam ao longo do tempo, mas não tanto quanto a soja.

A erva-mate apresenta a menor produção da região, apresentando uma média produzida de 1.940,455 toneladas, tendo uma produção mínima de 275 toneladas e uma máxima de 4.765 toneladas ao longo de dez anos; a quantidade produzida quase não variou no período, uma vez que o desvio padrão variou pouco em relação à média.

A correlação é a medida padronizada de relação entre as variáveis e é calculada pela covariância, e assim como a covariância quanto mais próxima a zero, menor a relação entre as variáveis. A Tabela 3 apresenta a matriz de correlação entre as culturas produzidas no estado de Mato Grosso do Sul. 
Tabela 3. Matriz de correlação entre as culturas produzidas em Mato Grosso do Sul*

\begin{tabular}{l|llll}
\hline & Erva-mate & Soja & Milho & Cana-de-açúcar \\
\hline Erva-mate & 1,0000 & & & \\
Soja & $-0,7513$ & 1,0000 & & \\
Milho & $-0,7250$ & 0,8646 & 1,0000 & \\
Cana-de-açúcar & $-0,6678$ & 0,8810 & 0,7762 & 1,0000 \\
\hline
\end{tabular}

*nas regiões produtoras de erva-mate

Fonte: Elaborado pelos autores.

Pode-se analisar que todas as culturas apresentam uma correlação negativa com a erva-mate, ou seja, uma maior produção das outras culturas representa uma ameaça à produção de erva-mate, sendo que a cultura que tem uma maior correlação negativa com a erva-mate, nas regiões produtoras de erva-mate, é a soja com uma correlação de $-0,7513$, seguida por milho, com -0,7250, e cana-de-açúcar, com uma correlação de $-0,6678$, mas todas apresentam forte correlação negativa, o que caracteriza que as demais culturas produzidas no estado são culturas com processos produtivos competitivos com a erva-mate.

Observa-se que soja, milho e cana-de-açúcar não são produtos com processos de produção competitivos; assim, a quantidade produzida dessas culturas não sofre redução quando são produzidas ao mesmo tempo, ou seja, um aumento na produção de soja, por exemplo, não diminui a quantidade produzida de milho. Em relação à erva-mate, sua produção será prejudicada se aumentar a produção de soja, milho ou cana-de-açúcar.

\subsubsection{Análise entre Estados e Países Produtores de Erva-mate}

A Tabela 4 resume os dados estatísticos de erva-mate produzida nos estados de Mato Grosso do Sul, Paraná, Santa Catarina e Rio Grande do Sul, e dos países Argentina e Paraguai. 
Tabela 4. Estatística Descritiva para Estados e Países Produtores de Erva-mate

\begin{tabular}{lccccc}
\hline Variável & Observações & Média & $\begin{array}{l}\text { Desvio } \\
\text { Padrão }\end{array}$ & Mínimo & Máximo \\
\hline MS & 22 & 1906,318 & 1431,87 & 275 & 4765 \\
PR & 22 & 109370,6 & 41324,4 & 48524 & 169549 \\
SC & 22 & 60152,09 & 25960,61 & 33506 & 121203 \\
RS & 22 & 37193,68 & 13220,58 & 23095 & 67402 \\
ARG & 22 & 242856,3 & 64682,88 & 28677 & 310000 \\
PY & 22 & 69284,23 & 26326,06 & 6304 & 136589 \\
\hline
\end{tabular}

Onde MS é Mato Grosso do Sul, PR é Paraná, SC é Santa Catarina, RS é Rio Grande do Sul, ARG é Argentina e PY é Paraguai.

Fonte: Elaborado pelos autores.

Observa-se que a maior produtora durante o período estudado foi a Argentina, com uma quantidade média produzida no valor de $242.856,3$ toneladas, um mínimo de 28.667 toneladas e um máximo de 290.000 toneladas. O desvio padrão indica que a produção foi dispersa ao longo do tempo, por ser muito distante do valor da média.

O segundo maior produtor no período observado foi o estado do Paraná, com uma média produzida de 109.370,6 toneladas, com um mínimo de 48.524 toneladas e um máximo de 169.549 toneladas. O desvio padrão, por ser muito longe da média, indica que a produção possuiu valores que variam muito ao longo da série de tempo estudada.

Na terceira posição, encontra-se o Paraguai, que teve uma produção média de 69.284,06 toneladas, com quantidade mínima produzida de 6.304 toneladas e uma quantidade máxima de 136.589 toneladas. O desvio padrão indica que a dispersão da produção foi muito grande, pois se encontra tão longe da média.

O estado do Rio Grande do Sul encontra-se na quarta colocação de produtores de erva-mate, com uma produção média nos anos entre 1991 e 2011 de 37.193,68 toneladas, com uma produção máxima de 67.402 toneladas e a mínima de 23.095 toneladas, com uma produção que variou ao longo do tempo, pelo desvio padrão estar distante da média.

O quinto produtor de erva-mate foi Santa Catarina, que produziu no período de tempo estudado a quantidade média de 60.152,09 toneladas, com 
a quantidade máxima produzida de 121.203 toneladas e a mínima de 33.506 . O desvio padrão diz que a produção varia ao longo do tempo, pelo valor não estar tão próximo ao valor da média, mas não varia tanto quanto a produção do Paraná.

$\mathrm{Na}$ Tabela 5, tem-se a matriz de correlação entre os estados e os países produtores de erva-mate.

Tabela 5. Matriz de Correlação entre os Estados e os Países Produtores de Erva-mate

\begin{tabular}{c|cccccc}
\hline & MS & PR & SC & RS & ARG & PY \\
\hline MS & 1,0000 & & & & & \\
PR & $-0,9051$ & 1,0000 & & & & \\
SC & 0,6702 & $-0,7285$ & 1,0000 & & & \\
RS & 0,5703 & $-0,6887$ & 0,7321 & 1,0000 & & \\
ARG & $-0,3419$ & 0,3720 & $-0,3167$ & $-0,1093$ & 1,0000 & \\
PY & $-0,2403$ & 0,4660 & $-0,2715$ & $-0,0225$ & 0,6806 & 1,0000 \\
\hline
\end{tabular}

Onde MS é Mato Grosso do Sul, PR é Paraná, SC é Santa Catarina, RS é Rio Grande do Sul, ARG é Argentina e PY é Paraguai.

Fonte: Elaborado pelos autores.

Pode-se observar que as correlações negativas com o estado de Mato Grosso do Sul são as do estado do Paraná com uma maior correlação negativa de -0,9051; Argentina, com uma correlação negativa de -0,3419; e o Paraguai com -0,2403; e as demais regiões com correlações positivas com a produção do estado de Mato Grosso do Sul. A redução na produção de erva-mate em Mato Grosso do Sul ainda possui outros fatores, como os apontados por Daniel Omar (2009), inclusive o desmatamento da área com ervais nativos e as dificuldades dos agricultores geradas pelo Plano Real.

\subsection{PREVISÃO PARA PRODUÇÕES FUTURAS DE ERVA-MATE}

Considerando a equação: $Y_{t}=T_{t}+S_{t}+C_{t}+I_{t} Y_{t}=T_{t}+S_{t}+C_{t}+I_{t}$, e levando em conta que o modelo de previsão adotada não possui variações sazonais e nem variações cíclicas, as características da equação são apresentados na Tabela 6. 
Tabela 6. Características da previsão da produção de erva-mate em MS

\begin{tabular}{lll}
\hline Variável & Coeficiente & (Desvio Padrão) \\
\hline C & $3493,764^{*}$ & $(249,4685)$ \\
Tendência & $-204,185^{*}$ & $(20,53541)$ \\
D1 & $767,3074^{* * * *}(379,6397)$ \\
$\mathbf{R}^{2}$ Ajustado & 0,839100 \\
$\mathbf{R}^{2}$ & 0,822163 \\
Prob (F-statistic) & 0,00000 \\
\hline
\end{tabular}

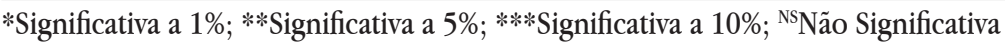

Fonte: Elaborado pelos autores.

Pela análise da regressão, vê-se que o modelo como um todo apresenta um bom poder de previsão $(82,21 \%)$ e, a partir da equação $Y_{t}=\hat{\beta}_{1} T_{t}+\hat{\beta}_{2} S_{t}+\hat{\beta}_{3} C_{t}+\hat{\beta}_{4} I_{t}+\alpha_{t}$, do modelo dos Mínimos Quadrados Ordinários (MQO), tem-se que a equação de previsão é igual a:

$$
\text { Erva }- \text { mate }=3493,764-204,185 T+767,3074 D
$$

Onde:

$\mathrm{T}=$ tendência (ano);

$\mathrm{D}=1$, para os anos onde ocorreu a queda da produção argentina e 0 para os demais anos.

Observa-se que a cada ano a produção de erva-mate em Mato Grosso do Sul caiu a uma taxa de 204,185/ano. A previsão para os anos de 2012 e 2013 apontam uma tendência de produção negativa, como se pode observar na Figura 6, pois, se não forem tomadas as devidas providências, não forem adotadas políticas que estimulem o setor, a produção de erva-mate no estado será insignificante, sendo produzido somente para subsistência, como se pode observar na Figura 6 . 


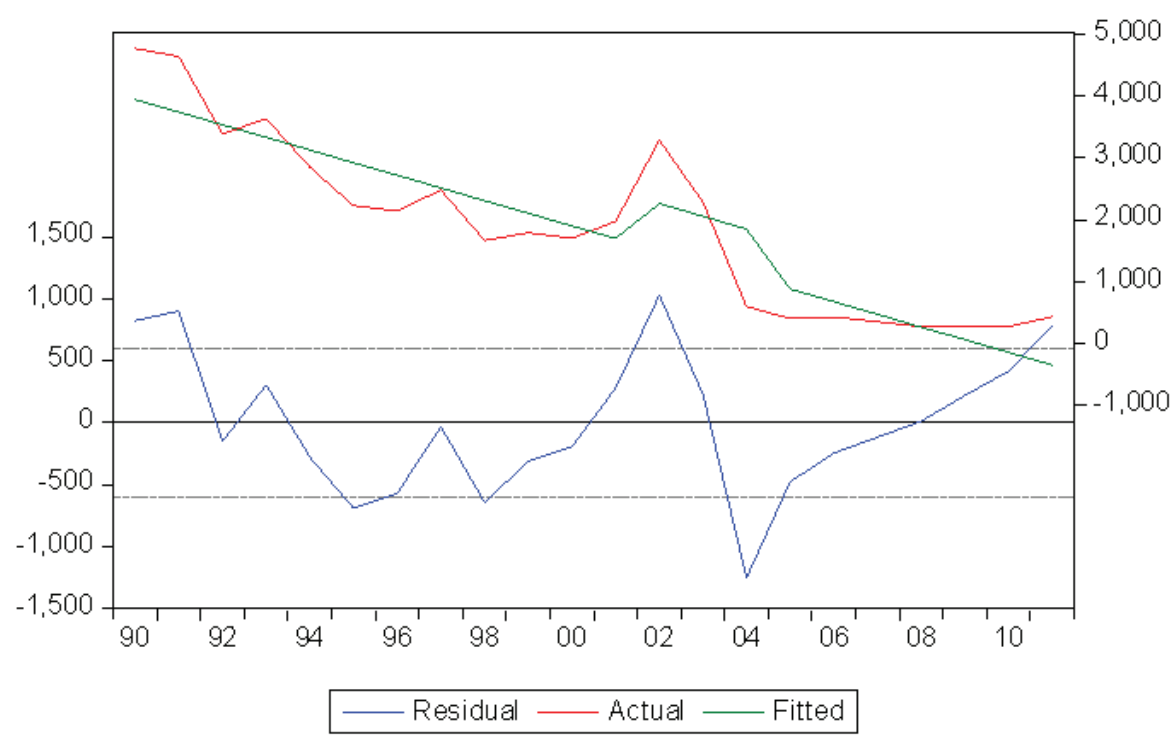

Figura 6. Previsão para a produção de erva-mate em Mato Grosso do Sul Fonte: Elaborado pelos autores.

Interpretando o gráfico, pode-se concluir que a produção ajustada (fitted) de erva-mate em Mato Grosso do Sul tende a ser negativa para os anos seguintes, de 2012 e 2013, ou seja, uma produção apenas de subsistência, não constando produção de erva-mate para Mato Grosso do Sul. A produção de erva-mate continuaria com o comportamento apresentado nas últimas décadas, declinando, e com impacto ainda maior na competitividade da erva-mate do estado com outras regiões.

\section{CONSIDERAÇÕES FINAIS}

A produção de erva-mate em Mato Grosso do Sul nas últimas décadas esteve muito abaixo da média histórica, ou seja, a produção no estado vem cada vez mais diminuindo, enquanto a produção de soja, milho e cana-de-açúcar apresenta um comportamento totalmente oposto, apresentando uma produção crescente ao longo da série de tempo estudada.

Todas as outras culturas utilizadas para comparação apresentam uma alta correlação negativa com a erva-mate, ou seja, todas as outras culturas são 
concorrentes da erva-mate, portanto, um aumento na produção de soja, milho, ou cana-de-açúcar, representa uma diminuição na produção de erva-mate, fazendo com que essa cultura perca sua importância econômica.

Nos outros estados brasileiros - Paraná, Santa Catarina e Rio Grande do Sul - a produção de erva-mate encontra-se acima da média histórica estudada, ou seja, apesar de não apresentar um crescimento constante ao longo do tempo, possuem uma produção estável. Os outros países produtores apresentam no final da série temporal um crescimento da produção. Sendo assim, Mato Grosso do Sul é a única região produtora que apresenta uma produção insignificante se comparada à produção total.

O estado do Paraná, a Argentina e o Paraguai possuem uma correlação negativa com a produção de erva-mate no estado de Mato Grosso do Sul. Assim, tanto Paraná quanto Argentina e Paraguai têm uma produção concorrente com a produção sul-mato-grossense, representando uma ameaça para a produção do estado de Mato Grosso do Sul, pois quanto maior a produção nessas regiões, menor a produção no estado.

A característica da produção de erva-mate em relação à cana-de-açúcar, soja e milho, é de processos produtivos competitivos, uma vez que se observa o sacrifício da produção de erva-mate, mesmo levando em consideração somente as regiões onde se produz a erva-mate, ou seja, a produção combinada entre as culturas favorece as demais, provavelmente pelas expectativas de preços de mercado serem maior para cana-de-açúcar, soja e milho.

As produções de milho, soja e cana-de-açúcar possuem características de processos produtivos complementares, sendo possível elevar a produção de soja, mesmo havendo a produção de milho e cana-de-açúcar, por exemplo. $\mathrm{Ou}$ seja, nenhuma produção desses produtos é prejudicada se ocorrer um aumento em outro, um cenário completamente diferente se relacionar qualquer um desses produtos com a erva-mate.

Pode-se considerar que a primeira hipótese, de que a perda de importância da erva-mate em Mato Grosso do Sul ocorre em virtude de sua substituição por outras culturas mais rentáveis; a segunda hipótese que diz que a perda de importância econômica da erva-mate ocorre devido à concorrência com outros estados e países 
vizinhos; e a terceira hipótese, de que a erva-mate possui um processo produtivo competitivo com as culturas de soja, milho e cana-de-açúcar, enfim, são todas aceitas.

A falta de apoio das instituições responsáveis pela agricultura em Mato Grosso do Sul no que diz respeito à erva-mate e falta de organização dos próprios produtores, diferente do que se observa em outros estados e países, e também a falta de pesquisas voltadas para o setor são, sem dúvidas, os principais motivos para a perda de importância econômica de um produto que já foi um grande potencial do estado.

\section{REFERÊNCIAS}

ARRUDA, G. Heródoto. 1984. In: INSTITUTO EUVALDO LODI. Ciclo da erva-mate em Mato Grosso do Sul 1883-1947. Campo Grande: Instituto Euvaldo Lodi, 1986. (Coletânea Séries Históricas).

BALDO. Almanaque. Disponível em: <http:/www.baldo.com.br/conhecimento/ almanaque/pt $>$. Acesso em: 04 jul. 2012.

CARMO, C. B. Erva-mate: potencialidades locais e inovação tecnológica do processo produtivo em área de fronteira do estado de Mato Grosso do Sul. 2007. $137 f$. Dissertação (Mestrado Acadêmico) - Universidade Católica Dom Bosco, Programa de Pós-Graduação em Desenvolvimento Local, Campo Grande, 2007.

DANIEL, O. Erva-mate: sistema de produção e processamento industrial. Dourados: Ed. da UFGD, 2009.

DOS SANTOS, M. L.; LÍRIO, V. S.; VIEIRA, W. D. C. Microeconomia aplicada. Viçosa: Biblioteca Central da UFV, 2009.

FAOSTAT. Disponível em: < http://www.faostat.fao.org > Acesso em: 18 set. 2011.

FERNANDES, V. B. A. Argentina: crise e recuperação. Conjuntura Internacional da PUC-Minas, 14 de novembro de 2003.

GUJARATI, D. Econometria básica. 4. ed. Rio de Janeiro: Campus, 2006. 
HOFFMANN, R.; VIEIRA, S. Análise de regressão: uma introdução à econometria. São Paulo: Hucitec, 1977.

INSTITUTO BRASILEIRO DE GEOGRAFIA E ESTATÍSTICA. IBGE. Disponível em: <http:/http://www.ibge.gov.br/home/> . Acesso em: 14 fev. 2011.

INSTITUTO EUVALDO LODI. Ciclo da erva-mate em Mato Grosso do Sul 18831947. Campo Grande: Instituto Euvaldo Lodi, 1986. (Coletânea Séries Históricas).

MILESKI JUNIOR, A. M. Análise de métodos de previsão de demanda baseados em séries temporais em uma empresa do setor de perfumes e cosméticos. 2007. 117f. Dissertação (Mestrado em Engenharia de Produção e Sistemas) - Pontifícia Universidade Católica do Paraná - UCP, Curitiba, 2007.

LAKATOS, E. M.; MARCONI, M. A. de. Fundamentos de metodologia científica. 6. ed. São Paulo: Atlas, 2006.

LIMA, R. Q. Identificação de parâmetros pelo método dos mínimos quadrados não linear. 2009. 62f. Relatório (Projeto de Iniciação Científica) - Pontifícia Universidade Católica, Rio de Janeiro, 2009.

MEDRI, W. Análise exploratória de dados. Londrina: UEL, 2011. (Curso de especialização "Lato Sensu" em estatística).

MONTELLA, M. Micro e macroeconomia: uma abordagem comercial e prática. São Paulo: Atlas, 2009.

PEREIRA, B. B. A influência das instituições financeiras sobre o mercado futuro de dólar. São Paulo: USP, 2011.

PETERNELLI, A. L. Info 162. UNC. Disponível em: < http:/http://www.cpc.unc.edu/ measure/training/materials/data-quality-portuguese/Estatistica.pdf $>$. Acesso em: 13 maio 2013.

SALDANHA, A. Capataz Caati. 1984. In: INSTITUTO EUVALDO LODI. Ciclo da ervamate em Mato Grosso do Sul 1883-1947. Campo Grande: Instituto Euvaldo Lodi, 1986. (Coletânea Séries Históricas). 
SANTANA JUNIOR, J. R. Formação territorial da região da Grande Dourados. Geografia (Londrina), v. 18, n. 2, p. 89-107, 2009.

SECRETARIA DE ESTADO DE MEIO AMBIENTE, DO PLANEJAMENTO, DA CIÊNCIA E TECNOLOGIA. SEMAC. Zoneamento ecológico-econômico de Mato Grosso do Sul. Disponível em: < http://www.semac.ms.gov.br/zeems/>. Acesso em: 02 jun. 2013.

SEREJO, H. Caraí. 1984. In: INSTITUTO EUVALDO LODI. Ciclo da erva-mate em Mato Grosso do Sul 1883-1947. Campo Grande: Instituto Euvaldo Lodi, 1986. (Coletânea Séries Históricas).

ZAMBERLAN, C. O. et al. Análise da industrialização sul-mato-grossense em face da industrialização brasileira. Revista Brasileira de Gestão e Desenvolvimento Regional, Taubaté, v. 6, n. 3, 2010.

Recebido em: 05 de dezembro de 2013 Aceito em: 26 de fevereiro de 2014 